\title{
Development of a remote tending system for analog broadcast transmitters
}

\author{
Gerino Mappatao, Isaiah Mari Zebedia Bautista, Marc Kevin Orsos, Mark Aldrine Ribo, \\ Joseph Castillo \\ Department of Electronics and Communications Engineering, De La Salle University, Philippines
}

\begin{tabular}{|c|c|}
\hline Article Info & ABSTRACT \\
\hline Article history: & \multirow{10}{*}{$\begin{array}{l}\text { Whenever a broadcast transmitter is on-air, it is required to be tended by } \\
\text { licensed broadcast technicians. Technicians periodically monitor the } \\
\text { transmitter performance, record the supply voltage and current at the last } \\
\text { stage of the power amplifier and keeps a copy for at least two years. Also } \\
\text { recorded are the times the transmitter is turned ON and OFF as well as the } \\
\text { times the transmitter shuts down and returns back to air. This paper proposes } \\
\text { a system to remotely tend analog transmitters in one central monitoring } \\
\text { station. The remote tending of several transmitters in one location is made } \\
\text { possible through internet connection. However, the challenge in the proposed } \\
\text { system is in the gathering of transmitter data. A prototype of the system was } \\
\text { constructed and tested in an FM broadcast transmitter. Test results on the } \\
\text { prototype performance show that the proposed system can effectively be } \\
\text { used to remotely monitor, record data and control the status of analog } \\
\text { broadcast transmitters. The primary feature of the proposed system of } \\
\text { monitoring several transmitters in one location will bring cost effective } \\
\text { advantages to the broadcast operators. }\end{array}$} \\
\hline Received Jan 20, 2019 & \\
\hline Mar 30, 2019 & \\
\hline Accepted Apr 31, 2019 & \\
\hline Keywords: & \\
\hline Analog transmitter & \\
\hline Analog transmitter control & \\
\hline Analog transmitter monitoring & \\
\hline Remote metering & \\
\hline Remote monitoring & \\
\hline
\end{tabular}

Copyright $\odot 2019$ Institute of Advanced Engineering and Science. All rights reserved.

\section{Corresponding Author:}

Gerino Mappatao,

Department of Electronics and Communications Engineering,

De La Salle University,

2401 Taft Avenue, Malate, Manila, Philippines.

Email: gerino.mappatao@dlsu.edu.ph

\section{INTRODUCTION}

The National Telecommunications Commission of the Philippines and regulatory bodies of other countries require technicians to continuously monitor the performance of broadcast transmitters whenever they are on-air. Meter readings of transmitters are recorded every 30 minutes in a logbook. The logs are saved for at least two years $[1,2]$. Also included to be logged are the exact times the transmitter is turned ON and turned OFF everyday, or at any time the transmitter goes off-air and when it returns to air again. These daily routines executed by technicians on a daily basis is the aim of the proposed system to accomplish in tending several analog transmitters.

Broadcast operators in the country maintain two types of transmitters: the modern and analog transmitters. Communcation ports are installed in modern transmitters that allow direct computer connection to them. Aside from the port, modern transmitters also have web interfaces to access information on transmitter operational condition that could be used for monitoring and control of the transmitter. Meter readings are displayed using LCDs (Liquid Crystal Displays).

Analog broadcast transmitters neither have access ports nor web interfaces. LED (Light Emitting Diode) or LCD displays are used in these transmitters to display meter readings. The acquisition of transmitter data from meters of these transmitter types that could be used for remote tending is quite a problem. This paper proposes a system that could monitor, log and control the operation of several analog 
broadcast transmitters. Specifically, it presents the methods of acquiring transmitter data, monitor present transmitter status, log previous data and a provision to print the same. A prototype was contructed and tested using an analog FM transmitter. Specifically, the analog transmitter used in the prototype is a HT-35CD Harris FM transmitter presently being used by Metro Manila's Magic 89.9 MHz, owned and operated by Quest Broadcasting, Inc.

Figure 1 shows the block diagram of the proposed system. The system is basically composed of (1) the CMC (Central Monitoring Computer), (2) server at each transmitter, (3) GSM module, and (4) data acquisition systems. The CMC is located in the central station where all data are destined to be received. The transmitter data are: Voltage and current at the last stage of the transmitter power amplifier (PA); power related data, i.e. incident and reflected transmitter power; and the time the data are taken. It receives transmitter data from each transmitter being tended every half-an-hour as required by regulatory bodies. The CMC also sends command signals to the transmitter servers for transmitter powering and control, and request for data retransmission. It is also at the $\mathrm{CMC}$ where previous data are stored and printed if desired.

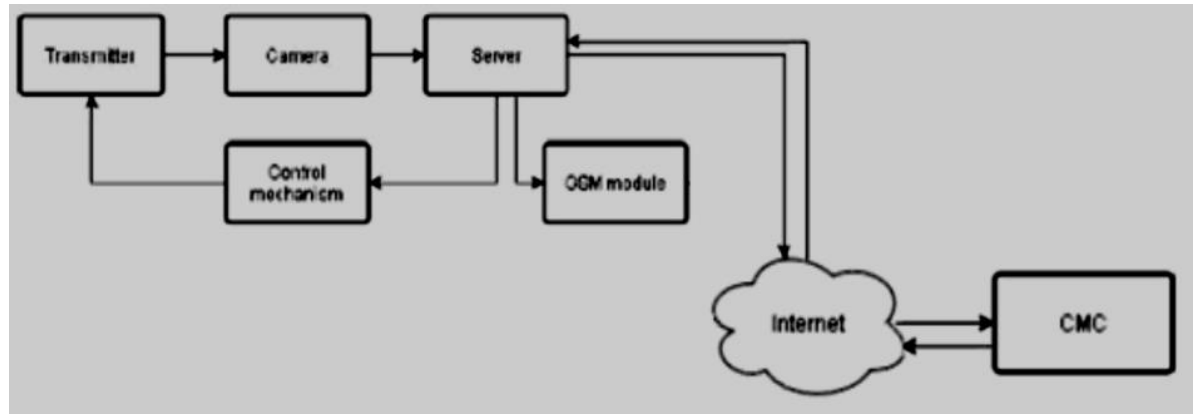

Figure 1. Block diagram of the proposed system for the remote monitoring, logging and control of modern transmitters

At the transmitter site, the server communicates with the CMC through the internet. The server gathers, stores and sends transmitter dat to the CMC. The GSM module is located at the transmitter site and it sends SMS (Short Message Service) to alert the tender at the CMC of any eventuality that needs prompt attention, e.g. SWR exceeds the value of 1.8 .

The system also contains a transmitter data acquisition system. It is basically a system that converts the meter readings on an LED/LCD display to transmitter data to be saved locally and be sent to the CMC. Data acquisition in analog transmitters is a difficult job since there are no ports or interfaces provided for this purpose. The acquisition scheme in the implementation uses solenoids to change the transmitter display setting, and a camera to capture the displayed data. The whole data acquisition scheme is discussed later in this paper.

There are similar systems developed in the past but mostly on the remote monitoring and control only of modern type transmitters. Such a system is described in [3]. The said system is used in monitoring and control of modern broadcast transmitters using an embedded system. Also, it does not have the capability to log data. In terms of implementation, remote control system implementations that find applications in broadcasting are discussed in [4-8], particularly on the use of control algorithms. However, gathering of data from analog transmitters are not discussed.

\section{SYSTEM DESIGN}

The design of the proposed system is based on the use of an anlog FM transmitter whose front panel is shown in Figure 2(a). Its features are much similar with other brands of the analog type. It has an LED/LCD display where meter readings are displayed one at a time, and buttons are pressed to display a set of readings alternately, one after the other. These readings are values of transmitter parameters such as plate voltage, plate current, transmitter output power, etc. In the implementation of the system, solenoids are used to remotely press the buttons shown on the front panel of the transmitter to change the parameter value being displayed. The transmitter also has a terminal block at the rear panel to turn ON/OFF the power switch and to vary the output power of the transmitter. This is shown in Figure 2(b). 


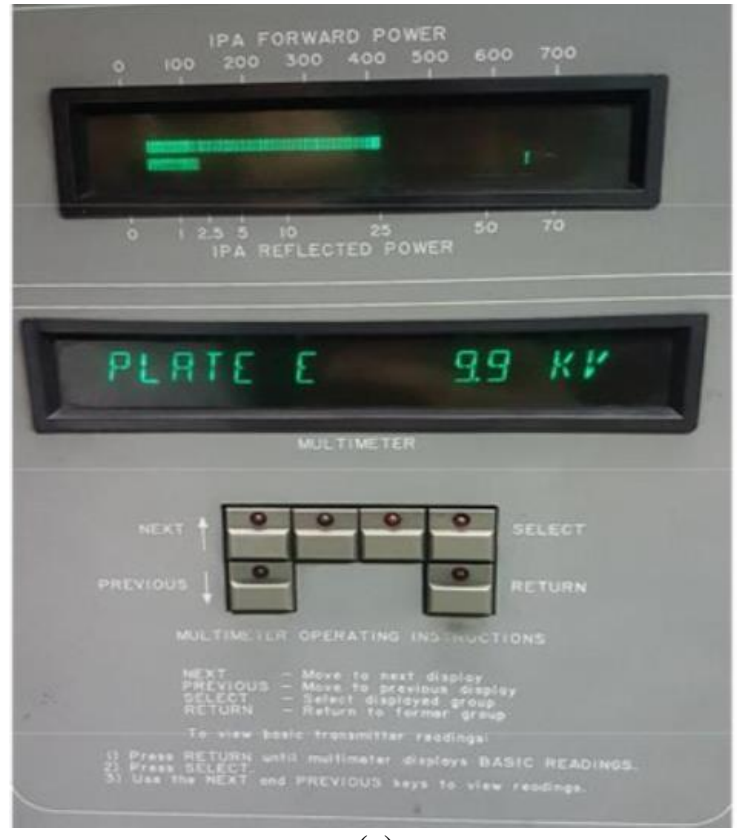

(a)

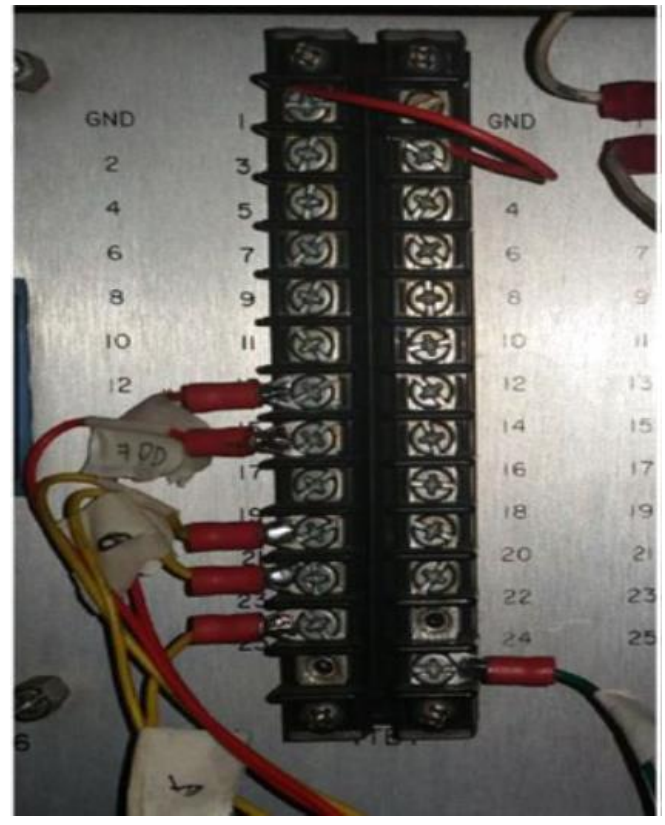

(b)

Figure 2. Harris FM transmitter used in the implementation: Front panel (left) and Rear panel (right)

The design of the system leads towards the realization of the functions of the two major parts: The Server and the CMC. In the server, there exists a data gathering system to read the meter readings on the voltage and current of the transmitter final stage, incident and reflected transmitter power, and SWR. The data gathering system also has a mechanism to to press the necessary buttons to vary the meter settings.

In the CMC, a GUI (Graphical User Interface) is developed for the display of the present transmitter data, the status of the transmitter, etc. It is also in the CMC where a database of the logged transmitter data are saved in Excel format. In essence, the design of the proposed system is composed of the design of the following: (1) analog transmitter server, (2), the data gathering system, (3) the CMC and (4) GSM alarm system.

\subsection{The Server}

The server is the located at the transmitter site and is used to store the gathered analog transmitter data of the analog transmitter and to be sent to the CMC. In the implementation, it is coded in Java that runs in the Netbeans IDE [9]. It uses multi-threading to run multiple classes at once. It uses a program that creates sockets; these sockets are used to connect the server to the CMC. Upon starting the thread, different server sockets will be created and will wait for the CMC to connect to it. A port number is assigned to each server socket as shown in Table 1. These port numbers are the same with the port numbers at the CMC so that the right processes will match the sending and receiving codes. However, no port numbers are assigned to realtime and logging threads since these are local to the transmitter. Upon opening a socket, input and output streams are created for the receiving and sending of data, respectively.

The data flowchart shown in Figure 3 illustrates the threads for python, real-time, logging and status. The python thread accepts data coming from the Visual Studio program. It records the received string and the value to a Java method so that it can be called by the real-time thread. The real-time thread sends the real-time values to the CMC. Upon changing the parameter display using the solenoids, the recorded values will also change. Since analog transmitters can only display one parameter (e.g. voltmeter reading) at a time, the real-time thread has a switch case where its status depends on the received string. Every string will record the meter reading that will later be logged as transmitter data. In the logging thread, a loop is used to check the current minute of the computer time. If the time is at 00 or 30 , the thread will start logging the parameters to the database. If the CMC is connected, it will also send the logged data.

The status thread monitors the SWR. If the value is high compared to a preset value (1.8), or if it returns to normal from a high value, the system will send a GSM text message corresponding to the status of the transmitter. The status thread also monitors the turning ON and OFF of the transmitter and also sends corresponding text messages. 


\begin{tabular}{ll}
\multicolumn{1}{c}{ Table 1. Transmitter Server Packages } \\
\hline Thread & Port \\
\hline Real-time & - \\
Logging & - \\
Real-time sending & 90 \\
Log sending & 91 \\
Status sending & 6705 \\
Python & 6799 \\
Automatic SWR Check & 6704 \\
Manual SWR Check & 6703 \\
Solenoid & 6780 \\
Retransmission & 6792 \\
Specific Retransmission & 6793 \\
Alert Retransmission & 6810 \\
Specific Alert Retransmission & 6812 \\
Power Retransmission & 6811 \\
Specific Power Retransmission & 6813 \\
\hline
\end{tabular}

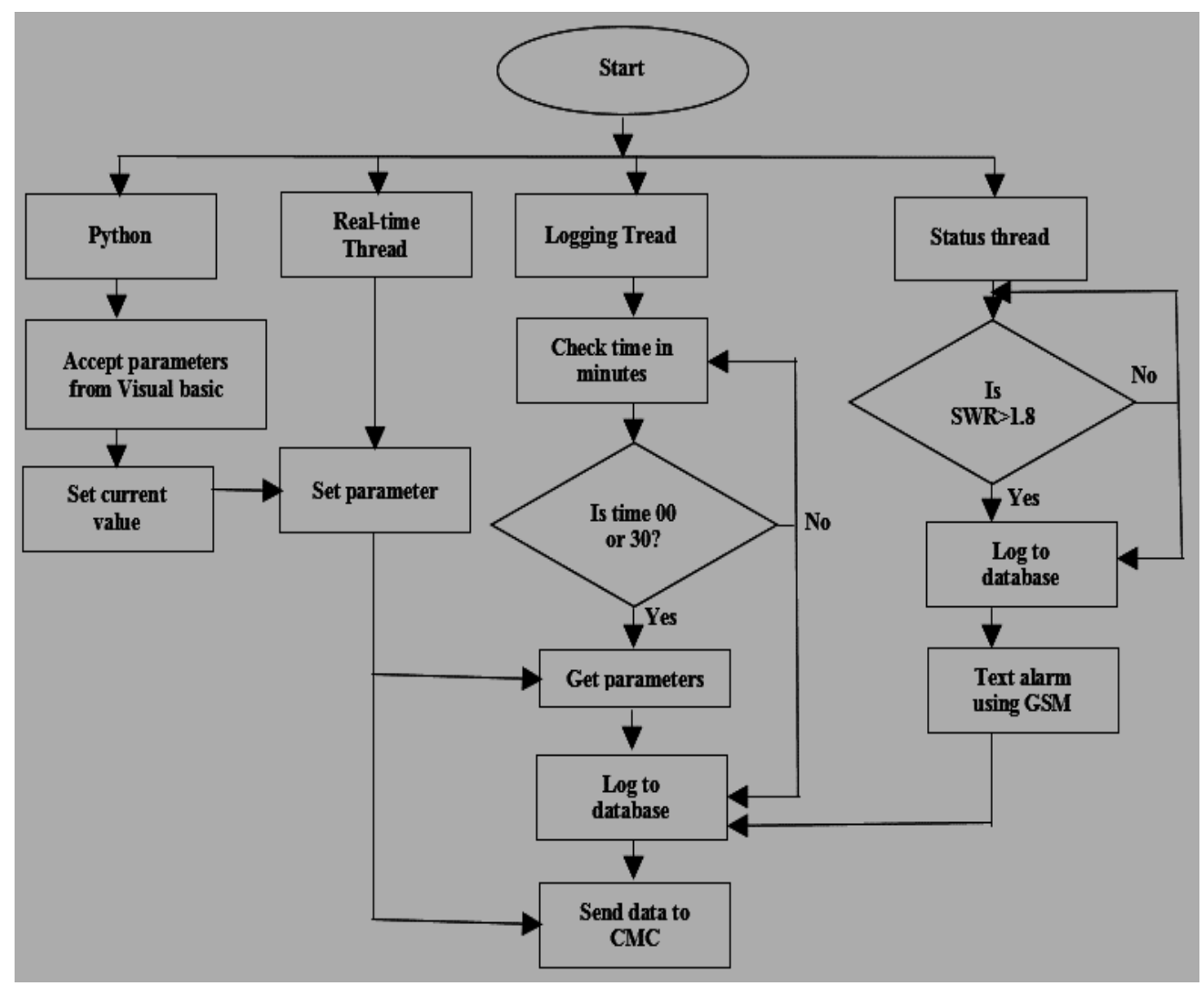

Figure 3. Data flowchart

\subsection{Data Gathering System}

The Data Gathering System is composed of the control mechanism and the computer vision parts. The transmitter control mechanism pertains to the hardware used to control the analog transmitter. To manually control the transmitter, technicians press several buttons on the front panel of the transmitter to navigate the transmitter display, adjust the power, and to turn on/off the transmitter. The analog transmitter control mechanism serves the pupose of pressing the buttons at the transmitter that are remotely activated at the CMC. Figure 4 shows the flow diagram of the control mechanism. Shown in the figure, the local server waits and listens for commands coming from the central computer. When a power control or multimeter control command is received at the local server, it instructs the micro-controller to activate the necessary solenoids or relays corresponding to the comand. Even when the server is idly waiting for commands, it commence its 30 minute logging procedure and 3-minute SWR checking interval. 


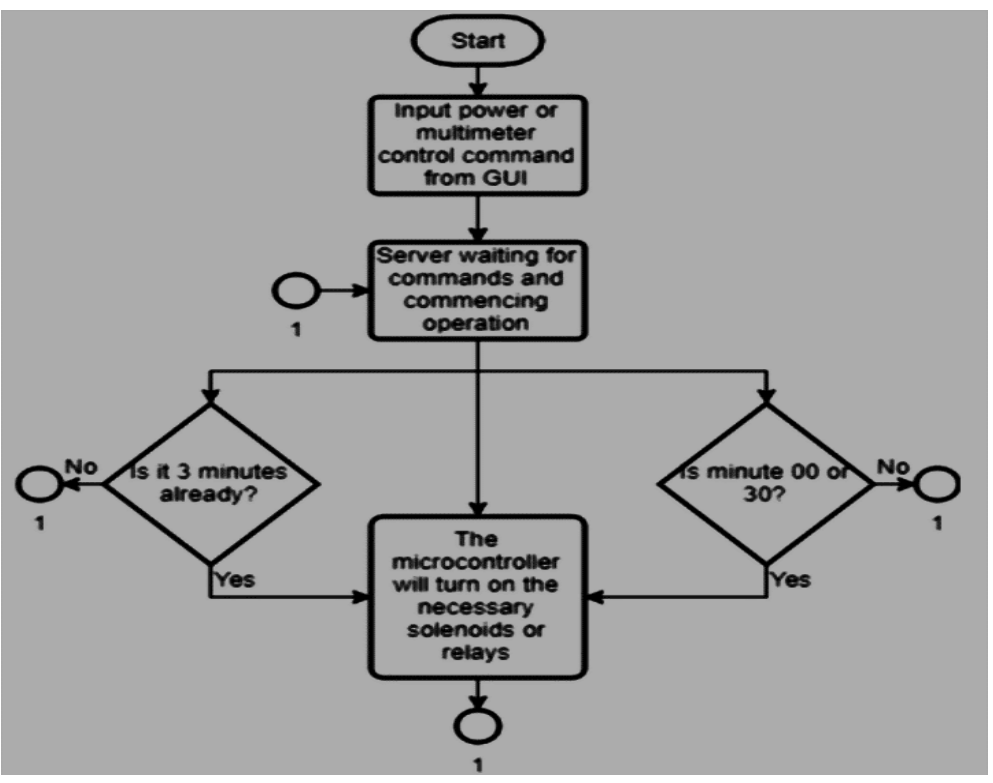

Figure 4. Flow chart of the control mechanism used in the prototype

There are two different control schemes implemented for the control mechanism: control of solenoids for navigating the display; and the turning on/off the transmitter. In the former, four solenoids were attached to the buttons on the transmitter front panel earlier described. Figure 5(a) shows the push-pull type solenoids used in the implementation. Figure 5(b) shows the solenoid mounted on the faceplate of the transmitter for the control of the multimeter display namely, next, previous, select and return. These four buttons are necessary to navigate and change the displayed transmitter parameter. The solenoids used to press the buttons and are controlled by an Arduino Nano micro-controller. Through a computer program and the micro-controller, the solenoids are used to press the buttons automatically to allow data collection. The solenoids can also be manually remote controlled when a command is entered from the CMC through the GUI bottons.

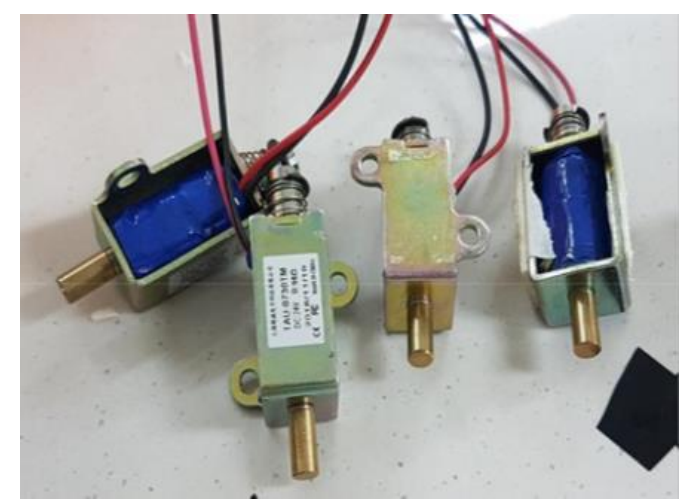

(a)

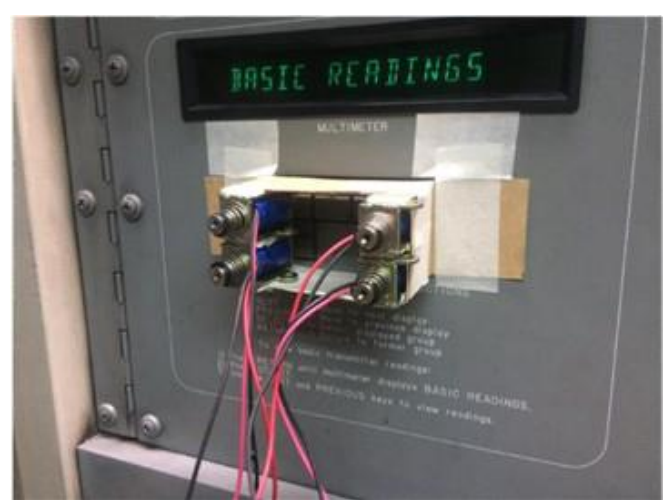

(b)

Figure 5. Push-pull type solenoids (left) mounted on the control buttons (right) of the transmitter front panel

The turning on/off of the transmitter is implemented using the available terminal block at the rear panel of the transmitter earlier shown in Figure 2(b). With the availability of terminal blocks, electromechanical relays were used instead of solenoids to control the power of the transmitter. The terminals used in the implementation of the functions of the proposed system are illustrated in Figure 6. These are the terminals in the block that are used to remotely control the transmitter: lower power, raise power, plate on, plate off and filament on command terminals. The switches in Figure 6 are the switches in several relays. The 
micro-controller where the relays are connected is programmed to act like a push button, when a command is received the output pin will go to the high state momentarily then goes to low state. Terminals 13 and 15 lowers and raises transmitter power, respectively. Transmitter power is varied using these terminals and the amount of variation depends on the duration of the applied voltage to either of the terminals. Also, it is necessary to set the display to the screen voltage of the power amplifier first before varying the power because the screen voltage changes when the power is changed. Turning off the transmitter is as simple as applying a voltage to terminal 21 , the plate off command. However, since analog transmitters are still made up of vacuum tubes, it is imperative for the filament to be warmed-up first. So, the micro-controller was programmed to first activate the filament on command to warm it up and after three minutes the plate on command will be activated and the transmitter will commence normal operation from there.

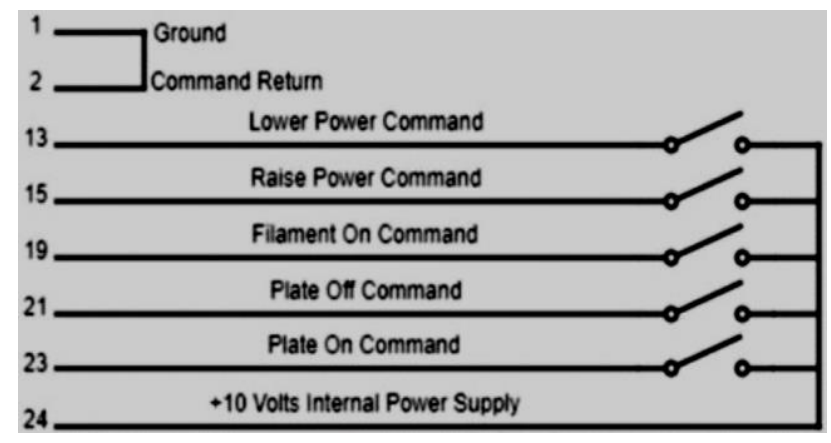

Figure 6. Terminals at the rear panel of the transmitter for the power control of the transmitter

After the presentation of the remote navigation of the display, the conversion of the characters shown on the display to become transmitter data is presented next. The characters are captured using a Logitech C525 720HD webcam. The camera reads the displayed characters and converts them to string so that it could be delivered to the server. At the start of the code developed for this purpose, the camera takes a picture of the display. The equivalent edge map is taken by filtering the captured image with a grayscale and blur before subjecting it to Canny edge detection. The location of the display on the image is then searched with the use of contours on the edge map. A perspective transform, specifically threshold and morphological transformation, is used to get a straight look on the display. Closing, a morphological noise removal, is used to remove most of the noise on the picture. With the contents of the display cleaned out, next is to inspect around the display for the characters by using contours again. Contours found are bounded in a box and if they meet the criteria for the width and length boundaries, they are assumed to be characters or digits. Once all the possible digits are found, their region of interest is taken to prepare for segment reading where each of the 16 segments are checked if they are present on the digit, denoting 1 if that segment is in use and 0 if the segment is blank. After getting the combination of $1 \mathrm{~s}$ and $0 \mathrm{~s}$, it is looked up on a table where the digits and their possible combinations are located. This is repeated until every digit has been identified. Finally, the letters and numbers are grouped accordingly before being sent to the database.

\subsection{The CMC}

The CMC is where the transmitters are monitored and controlled. Received data from several transmitters are also monitored, logged and printed, if needed. It basically contains the GUI (Graphical User Interface) and a database. The GUI is programmed and designed to display the current transmitter status, real-time data, as well as the logged data. The GUI will not only be passively receiving data but it can also send data from the control buttons to the transmitter in the interface. The database contains the stored data; if there is a need for data to be presented, an Excel file is generated that contains the logged transmitter data.

The GUI is first designed to handle several different transmitters. Although in the implementation, only a transmitter is used by a Class A FM broadcast station operating in Mandaluyong City, Philippines is used. The GUI of the said transmitter and an auxiliary transmitter is shown in Figure 7. The real-time value displayed in the GUI is the current value on the LED/LCD display. Four buttons, similar to the bottons on the front panel of the transmitter, are used to change the currently displayed parameter. For power control, clicking the increase/decrease buttons creates short holding motions in the push-pull solenoids at the transmitter site. The GUI also displays the immediate transmitter data that were received on a 30-minute interval. Lastly, the check SWR button navigates the LED/LCD display to determine the Incident and Reflected transmitter power. The SWR is then computed automatically using these values. 


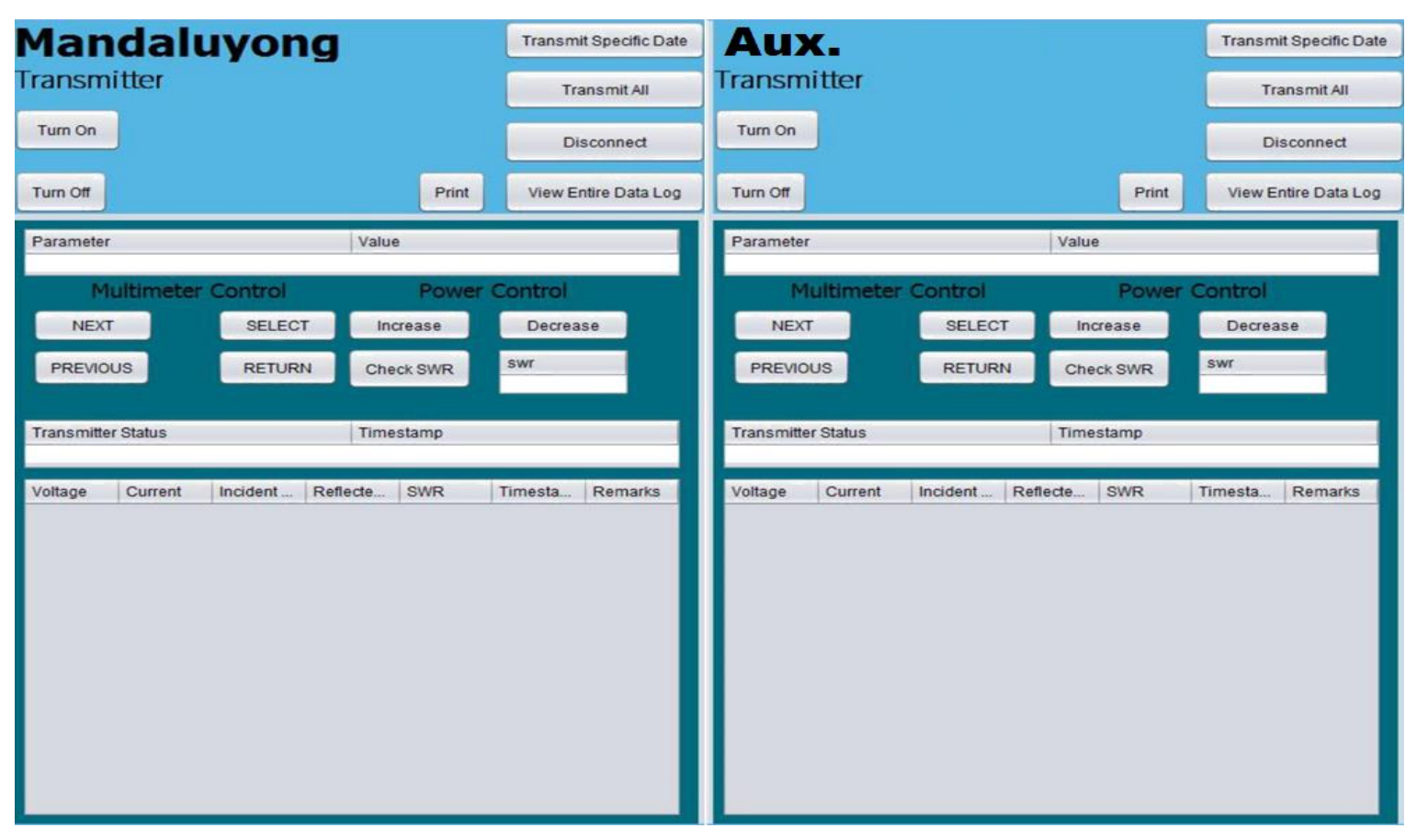

Figure 7. The GUI of the FM station operating in Mandaluyong City, Philippines

As shown also in the GUI, power switching buttons located at the upper left-hand portion are provided for each transmitter. These buttons, when pressed, send command signal to the transmitter computer to turn on or turn off the transmitter. If missing data need to be retransmitted, a command signal is sent by pressing the Transmit Specific Date button. On the other hand, Transmit All button will request the transmitter server to retransmit all data starting from the last row logged in the Excel file. After retransmitting the real time, transmitter status and logging thread will begin and display necessary data on their corresponding tables. The third button at the right side is the disconnect button which closes the socket of the threads. When internet interruption occurs, it is necessary to first close the sockets of the threads before pressing the Transmit All button, again to prevent errors from being generated. The fourth button at the right side is the View Entire Data Log button; it opens the excel file where data is logged. The Print button allows the printing of the excel file.

\subsection{GSM Alarm System}

The GSM Alarm system is implemented using SIM800L, an inexpensive, low power-consumption and four-band module board. Aside from SMS, it can also transmit data and voice. In order to implement the GSM alarm system, the SIM800L was connected to the Gizduino, via TX and RX pins. TX pin of SIM800L is connected to the pin2 of the gizduino and RX pin was connected to pin13. The SIM800L module needs a power supply input of $4 \mathrm{v}$ and $2 \mathrm{~A}$. It was implemented using a voltage converter, converting $5 \mathrm{~V}$ to $4 \mathrm{~V}$ from a bandspeed adapter connected to an outlet. The GSM arduino code is activated by the Java code of the server for SMS alert measages to be transmitted [10-25].

\section{RESULTS AND DISCUSSION}

The prototype of the proposed system was tested using the transmitter of a Class A FM station operating in Metro Manila, Philippines and the results of these tests are presented.

\subsection{Logging at the CMC}

To comply with the logging requirements of regulatory bodies, transmitter data are saved in Excel files at the CMC. The transmitter data can be printed based on particular dates specified by the user. Also, a separate file is created for each transmitter being tendered. A sample of an Excel file and a printed copy created at the CMC are shown in Figure 8. 


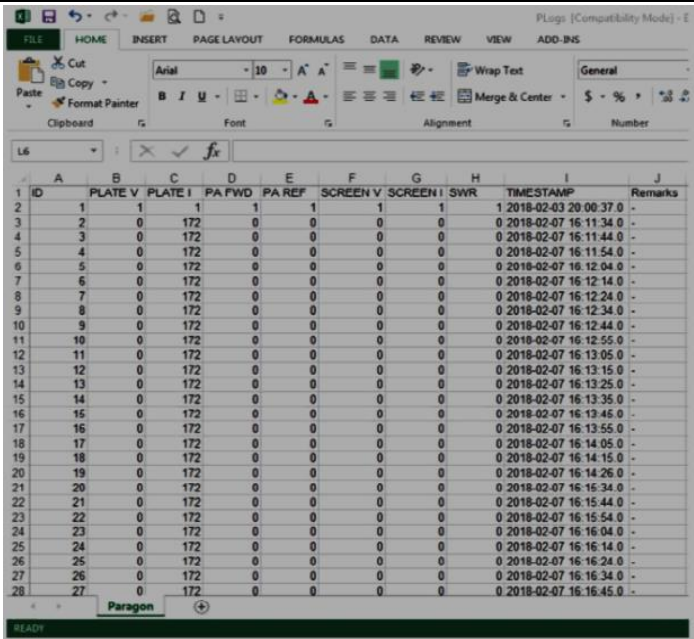

\begin{tabular}{|c|c|c|c|c|c|c|c|c|c|}
\hline & & & ind & & Quest B & 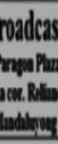 & If. $\ln C$ & & \\
\hline & $\begin{array}{l}\text { TRANSW } \\
\text { HT. } 23 C D \\
\text { MPO-108 }\end{array}$ & $\begin{array}{l}\text { TTER LOG } \\
\text { HARRIS } \\
\text { 8-00002 }\end{array}$ & & & & & & DATE: & $2018-02.21$ \\
\hline PLATEV & PUATEI & PAFND & PAREF & SCREE & IISCREE| & ISWR & Timesta & & Remarks \\
\hline 9.8 & 1.81 & 14.2 & 000 & 779 & 103 & 1.139 & $2018-02$ & 100000220 & \\
\hline 9.9 & 1.81 & 14.3 & 0 & 1 & 103 & 1 & 2018.02 & $2100: 30: 22.0$ & \\
\hline 9.9 & 182 & 14.4 & 008 & 1 & 1032 & 1.181 & 2018.02 & $2101: 00: 220$ & \\
\hline 5.8 & 1.82 & 14.4 & 008 & 780 & 1042 & 1.161 & 2018.02 & $2101: 30: 22.0$ & \\
\hline 9.9 & 1.82 & 14.4 & 088 & 1 & 1032 & 1.857 & 2018.02 & 2102000.22 .0 & \\
\hline 58.3 & 182 & 14.4 & 008 & 1 & 184.7 & 1.181 & 2018.02 & $2102: 30: 22.0$ & \\
\hline 5.7 & 1.81 & 14.3 & 008 & 1 & 1032 & 1.162 & 2018.02 & $2103.00: 22.0$ & \\
\hline 3.8 & 182 & 14.4 & 008 & 1 & 1 & 1.181 & $2018 \cdot 02$ & $2103: 30: 220$. & \\
\hline 3.9 & 1.81 & 14.4 & 008 & 792 & 184 & 1.181 & 2018.02 & $2104: 00: 22.0$ & \\
\hline 5 & 1.82 & 14.4 & 008 & 1 & 1 & 1.181 & 2018.02 & $3104: 30: 22.0$ & \\
\hline
\end{tabular}

Figure 8. Screenshot of the analog transmitter data in Excel file (left) and printed (right)

\subsection{GUI Display}

Figure 9(a) shows a screenshot of a filled up GUI of the system. The displayed data on the GUI were compared to the outputs of the Netbeans IDE both in the local and central computers. The data in the central computer IDE (Figure 9(b) and the local IDE in the transmitter (Figure 9(c) are the same with the data in the GUI shown in Figure 9(a).

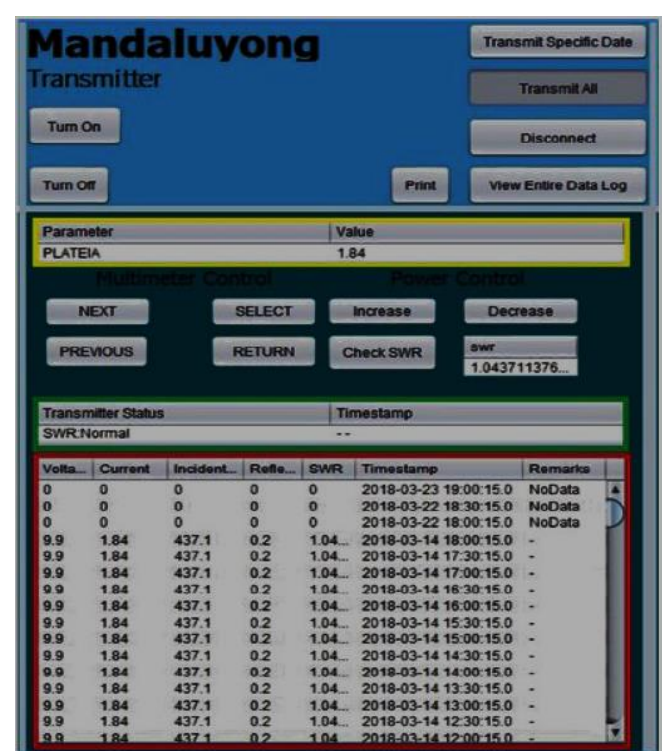

(a)

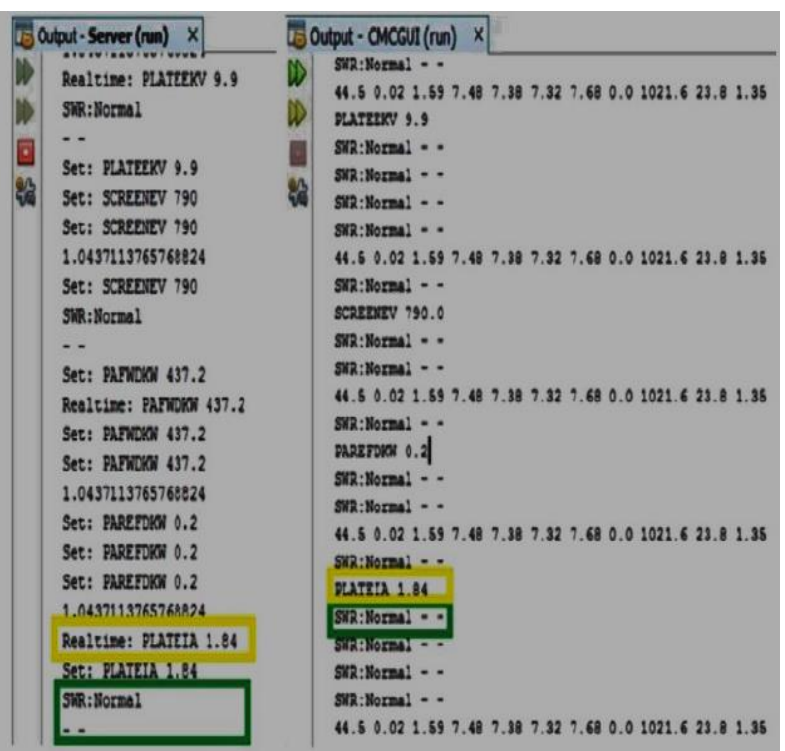

(b)

Figure 9. Transmitter data (a) displayed in the GUI, and (b) corresponding transmitter status output of the Netbeans IDE sent by the local computer (left) and received by the central computer (right)

\subsection{Transmitter Powering and Power Control}

In all tests conducted on power related functions, the proposed system responded accordingly to the commands sent from the central computer through the CMC. With the commands from the CMC and the relays at the transmitter site, the transmitter power was raised, lowered, turned on and off successfully. In the test done before the station signed-off, the transmitter power is increased by increasing the supply voltage from $4.51 \mathrm{kV}$ to $5.16 \mathrm{kV}$, varying the power from 907 watts to 1187 watts. On the other hand, the power is decreased by decreasing the supply voltage. When the Turn On button in the GUI is pressed, the relay for the Filament On command in the terminal block was activated to warm-up. After three minutes, the relay for the Plate On command was activated that turns-on the transmitter and begin normal operation. 


\subsection{GSM Alarm System}

There are four text messages that the GSM alarm system can send. These are (a) Warning: SWR has exceeded limit, (b) SWR is back to normal, (c) Transmitter is turned on, and (d) Warning: Transmitter is turned off. The first two are difficult to test. The transmitter is placed in a high risk situation if the SWR is forced to assume a high value or turning-off the transmitter during normal broadcasting activities. To test the functionality of the system on these, codes are used to simulate the occurrence of these transmitter conditions. Figure 10 shows the received messages as a result of the tests on the alarm system functionality.

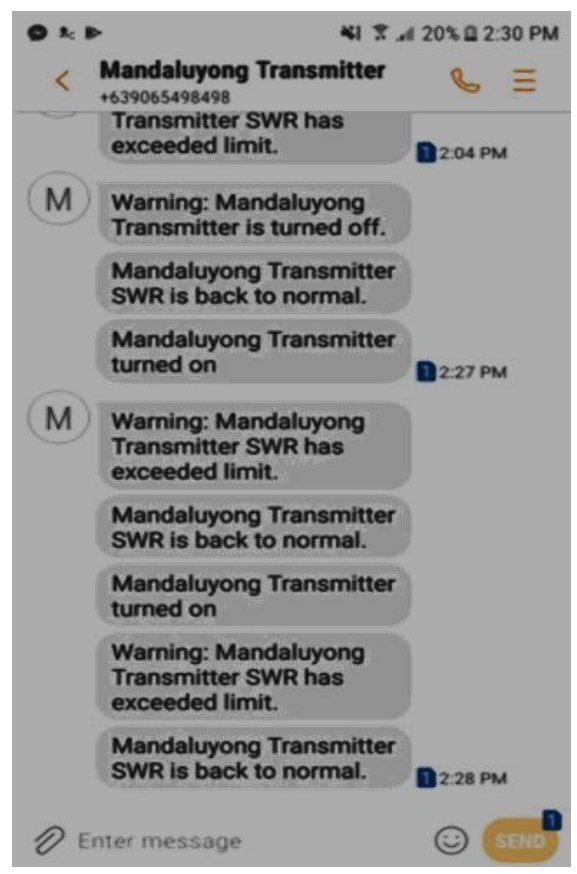

Figure 10. Screenshot of the text meassages received during the tests on the alarm features of the proposed system

\section{CONCLUSION}

Analog transitters are the forerunners of modern transmitters but they are still here to stay for a longer period in most countries. Analog transmitter data acquisition for remote tending is relatively more difficult than in their modern counterparts. However, based on the test results conducted on the prototype, the proposed system has the capacity to remotely tend the operation of analog transmitters and at the same time able to comply with the requirements of regulatory bodies. Aside, the system can also send alarm information to the CMC and through short measages during emergency situations. The system also has contingency fetures should data need to be resent. With the adoption of the proposed system for centralized tending of analog broadcast transmitters, broadcasting companies can save costs in tending multiple transmitters. Health hazards due to RF energy exposure on technicians and other transmitter personnel are avoided with the use of the proposed system. The system is ideal for unmanned transmitters in mountainous and remote locations.

\section{ACKNOWLEDGEMENTS}

The authors would like to thank Engr. Arman Ursal, Quest Broadcasting, Inc., DLSU-URCO and UNTV for the realization of this paper.

\section{REFERENCES}

[1] KBP, "Technical Standards and Operating Requiremnts for Broadcast Stations in the Philippines," 1991.

[2] J, C. Whitaker, "Standard Handbook of Broadcast Engineering", McGraw-Hill Standard Handbooks, 2005.

[3] Shu-ping Xu, et al., "The Design and Implement of Transmitter Remote Control System Based on the Embed Web Server," International Conference on Multimedia Technology, 2010, pp. 1-4. 
[4] E. Manir and S. M. Çinar, "On the Investigation of a Designed Smart Telemetry Control Algorithm," National Conference on Electrical, Electronics and Biomedical Engineering (ELECO), 2016, pp. 650-654.

[5] N. Kulkarni, S. V. N. L. Lalitha, S. A. Deokar, "Real time control and monitoring of grid power systems using cloud computing," International Journal of Electrical and Computer Engineering (IJECE), pp 941-949, 2019.

[6] G. Quoc-Anh, N. Dinh-Chinh, T. Duc-Nghia, T. Duc-Tan, K. Nguyen Thi, K. Sandrasegaran," Wireless Technology for Monitoring Site-specific Landslide in Vietnam," International Journal of Electrical and Computer Engineering (IJECE), pp 4448-4455, 2018.

[7] I. Mukhlash, D. Yuanda, M. Iqbal, "Mining Fuzzy Time Interval Periodic Patterns in Smart Home Data," International Journal of Electrical and Computer Engineering (IJECE), pp 3374-3385, 2018.

[8] B. S. Badreddine, E. A. Chaker, S. Denys, "Development of a Java-based Application for Environmental Remote Sensing Data Processing," International Journal of Electrical and Computer Engineering (IJECE), 2019.

[9] C. Fancy, L. M. M. Thanveer, "An evaluation of alternative protocols-based Virtual Private LAN Service (VPLS)," International Conference on IoT and Application (ICIOT), 2017, pp. 1-6.

[10] W. H. W. Hassan, A. Z. Jidin, S. A. C. Aziz, N. Rahim, "Flood Disaster Indicator of Water Level Monitoring System," International Journal of Electrical and Computer Engineering (IJECE), pp 1694-1699, 2019.

[11] P. W. Digarse and S. L. Patil, "Arduino UNO and GSM based wireless health monitoring system for patients," International Conference on Intelligent Computing and Control Systems (ICICCS), 2017, pp. 583-588.

[12] N. S. Ali, Z. A. A. Alyasseri, A. Abdulmohson, "Real-Time Heart Pulse Monitoring Technique Using Wireless Sensor Network and Mobile Application," International Journal of Electrical and Computer Engineering (IJECE), pp 5118-5126, 2018.

[13] H. Dahou, R. El Gouri, Mohammed Alareqi, K. Mateur, A. Mezouari, A. Zemmouri, L. Hlou, "Design and Implementation Intelligent Adaptive Front-lighting System of Automobile using Digital Technology on Arduino Board," International Journal of Electrical and Computer Engineering (IJECE), pp 521-529, 2018.

[14] T. S. Gunawan, Y. M. S. Munir, M. Kartiwi, H. Mansor, "Design and Implementation of Portable Outdoor Air Quality Measurement System using Arduino," International Journal of Electrical and Computer Engineering (IJECE), pp 280-290, 2018.

[15] M. I. Younis, T. F. Hussein, "Design and Implementation of a Contactless Smart House Network System," International Journal of Electrical and Computer Engineering (IJECE), pp 4663-4672, 2018.

[16] D. Mlakić, S. Nikolovski, E. Alibašić, "Designing Automatic Meter Reading System Using Open Source Hardware and Software," International Journal of Electrical and Computer Engineering (IJECE), pp 3282-3291, 2017.

[17] S. A. C. Aziz,A. F. Kadmin, N. Rahim, W. H. W. Hassan, I. F. A. Aziz, M. S. Hamid, R. A. Hamzah, "Development of automatic healthcare instruction system via movement gesture sensor for paralysis patient," International Journal of Electrical and Computer Engineering (IJECE), 2019.

[18] J. Howse, "Training detectors and recognizers in Python and OpenCV," IEEE International Symposium on Mixed and Augmented Reality (ISMAR), 2014, pp. 1-2.

[19] S. Fakhar A. G, A. Fauzan K, M. Saad H, R. Affendi H, K. H. Fen, "Development of a portable community video surveillance system," International Journal of Electrical and Computer Engineering (IJECE), pp 1819-1826, 2019.

[20] G. N. Solidakis, et al., "An Arduino-based subsystem for controlling UAVs through GSM," 6th International Conference on Modern Circuits and Systems Technologies (MOCAST), 2017, pp. 1-4.

[21] S. S. Arnob, A. S. Khan, R. Shelim, M. Chowdhury, "Safe sailing: GSM and GPS controlled autonomous boat with overweight detection and obstacle avoidance," Indonesian Journal of Electrical Engineering and Computer Science (IJEECS), pp 714-723, 2019.

[22] K. J. Yong, M. H. Salih, "Design and implementation of embedded auto car parking system using FPGA for emergency conditions," Indonesian Journal of Electrical Engineering and Computer Science (IJEECS), pp 876-883, 2019.

[23] M. Ahsan, R. Drolia, A. Kumar S, "Smart Walking Stick for the Visually Challenged," Indonesian Journal of Electrical Engineering and Computer Science (IJEECS), pp 1282-1288, 2018.

[24] N. A. A. Rahman, A. B. Jambek, "Biomedical health monitoring system design and analysis," Indonesian Journal of Electrical Engineering and Computer Science (IJEECS), pp 1056-1064, 2019.

[25] N. A. J. Salih,I. J. Hasan, N. I. Abdulkhaleq, "Design and implementation of a smart monitoring system for water quality of fish farms." Indonesian Journal of Electrical Engineering and Computer Science (IJEECS), pp 44-50, 2019.

\section{BIOGRAPHIES OF AUTHORS}

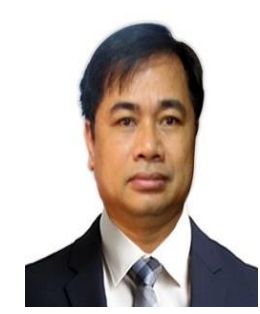

Gerino P. Mappatao was born in Tuao, Cagayan, Philippines. He received the B.S. degree in electronics and communications engineering (ECE) from Saint Louis University, Baguio City, Philippines in 1989, the M.S. and PhD degrees in ECE from De La Salle University-Manila, Philippines in 1998 and 2012, respectively. He is currently an Associate Professor of Electronics and Communications Engineering at De La Salle University-Manila. He authored and coauthored papers in conference proceedings and journals on antennas, broadcast engineering, wireless communications and image processing.

Isaiah Mari Zebedia S. Bautista was born in Manila, Philippines. He received the B.S. degree in 


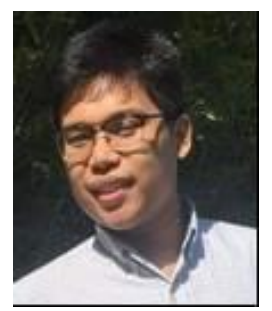

electronics and communications engineering (ECE) from De La Salle University, Manila in 2018. He is a former Assistant Vice President of the Electronics and Communications Engineering Society (ECES) and his research interests include Arduino microcontroller programming.

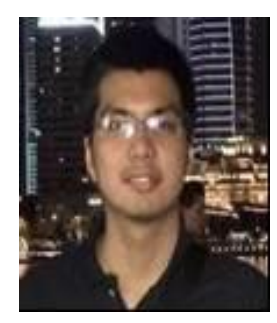

Joseph C. Castillo was born in Manila, Philippines. He received the B.S. degree in electronics and communications engineering (ECE) from De La Salle University, Manila in 2018. He is a former Vice President of the Electronics and Communications Engineering Society (ECES) and his research interests include Data Communications.

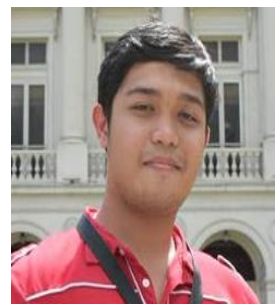

Marc Kevin J. Orsos was born in Manila, Philippines. He received the B.S. degree in electronics and communications engineering (ECE) from De La Salle University, Manila in 2018. He is a former Assistant Vice President of the Electronics and Communications Engineering Society (ECES) and his research interests include web development and computer vision.

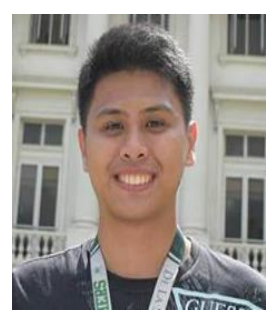

Mark Aldrine C. Ribo was born in Manila, Philippines. He received the B.S. degree in electronics and communications engineering (ECE) from De La Salle University Manila in 2018. His research interests include Java Programming. 